\title{
Successful Outcome of a Large Leiomyoma
}

\author{
Dr. Sajana Gogineni ${ }^{1}$, Professor in OBG \\ Dr. B. Anil Kumar ${ }^{2}$, Professor in General Surgery \\ Dr. B.N. Chander ${ }^{3}$, Professor in Radiology \\ ${ }^{I}$ (Dept. of OBG, Dr. PSIMS \& RF, Chinoutpalli, AP, India) \\ ${ }^{2}$ (Dept. of General Surgery, Dr. PSIMS \& RF, Chinoutpalli, AP, India) \\ ${ }^{3}$ (Dept. of Radiodiagnosis, Dr. PSIMS \& RF, Chinoutpalli, AP, India
}

\begin{abstract}
Leiomyomata of uterus are the most common benign tumors of the female genital tract. They present with symptoms such as excessive menstrual bleeding, dysmennorhoea, pelvic pain and discomfort. myomectomy is virtually always an option, even if a large number of fibroids are present or the tumors are very large or both. The uterus functions well in pregnancy after a myomectomy. Here we present a case of large leiomyoma in a $26 y$ old unmarried woman, who presented as mass per abdomen and discomfort without menstrual disturbances
\end{abstract}

Keywords: Leiomyoma, myomectomy, large fibroid

\section{Introduction}

Leiomyomata are the most common tumors of the uterus and female pelvis and are the most common cause of hysterectomies world wide. It is impossible to determine their true incidence accurately, although the frequently quoted incidence of $50 \%$ found at postmortem examinations seems reasonable ${ }^{1}$. They represent gonadal steroid-responsive aberrant clonal expansions of individual myometrial cells. The etiology is linked to somatic mutations and complex interactions of estrogen, progesterone and local growth factors ${ }^{2}$. Fibroid tumors that are asymptomatic can be left untreated as long as they are monitored closely. However, large uterine fibroids usually require surgical treatment.

\section{Case Report}

A 26 year old unmarried female came to gynaec opd, Dr.PSIMS \& RF with chief c/o mass per abdomen and abdominal discomfort of 3 months duration. There was no history of nausea, vomiting, loss of weight or appetite. No H/O bowel or bladder irregularity. She attained menarche at 13 yrs, her cycles were regular with normal flow. She had no menstrual irregularities. She denied prior sexual activity and use of hormones. There was no $\mathrm{H} / \mathrm{O}$ similar problems in the family. Her past $\mathrm{H} / \mathrm{O}$ and surgical $\mathrm{H} / \mathrm{O}$ were not significant. Her general and physical examination was normal.

On abdominal examination: there was a firm, non-tender, mobile mass corresponding to 30-32 Wks pregnant uterus size. The mass was mobile horizontally, but not in craniocaudal direction. Lower border of the mass was not felt. External genitalia were normal. P/S examination showed healthy vagina. Rectal mucosa was free. IVP done showed lateral displacement of ureters bilaterally with mild hydroureteronephrosis

USG examination showed a large midline mass arising from the uterus causing mild hydroureteronephrosis bilaterally probably sub-serous origin. MRI plain and contrast showed a large heterogenous mass of $24 \times 22 \times 10 \mathrm{cms}$ arising from the right side of myometrium displacing the rest of uterus to left side, probably a degenerated fibroid.

Case was posted for laparotomy. Introperative findings : large fibroid of size $26 \times 18 \times 10 \mathrm{cms}$ was seen arising mostly from the fundus and posterior myometrium, partly from anterior myometrium. Uterus was dextrorotated. Both ovaries were normal in size and echo pattern. Myomectomy was done and the myometrium was closed in layers. Tubal patency was confirmed by chrompertubation. The removed specimen was $2.8 \mathrm{kgs}$ in weight and measured $26 \times 22 \times 10 \mathrm{cms}$. Post operative period was uneventful.

Histopathological examination confirmed it as benign leiomyoma with areas of cystic, mucoid and red degeneration.

Follow up USG showed uterus of $8.8 \times 5.5 \times 6.5 \mathrm{cms}$ with normal size and echo pattern. Endometrial echoes measured $12 \mathrm{~mm}$. Patient resumed her menstrual cycle I month later. 


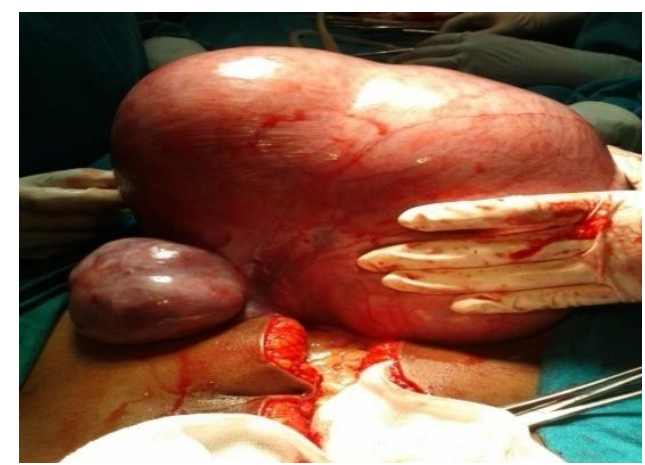

Fig 1: Intra operative picture showing large intramural fibroid

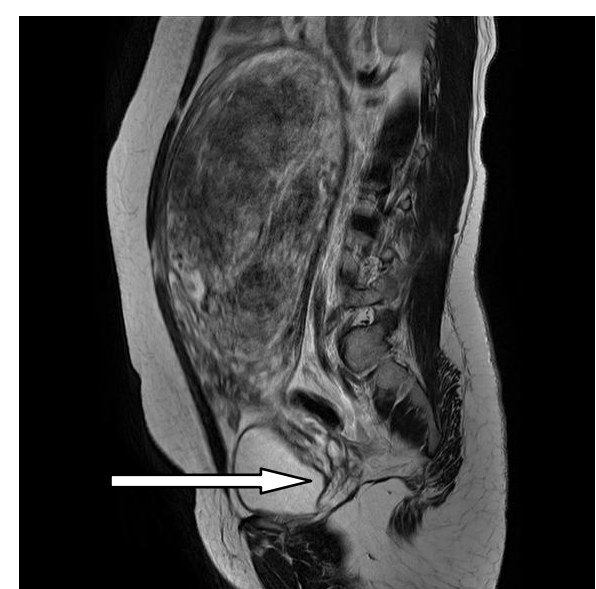

Fig 2: MRI T2W image showing large intramural fibroid. Arrow showing dextrorotated uterus

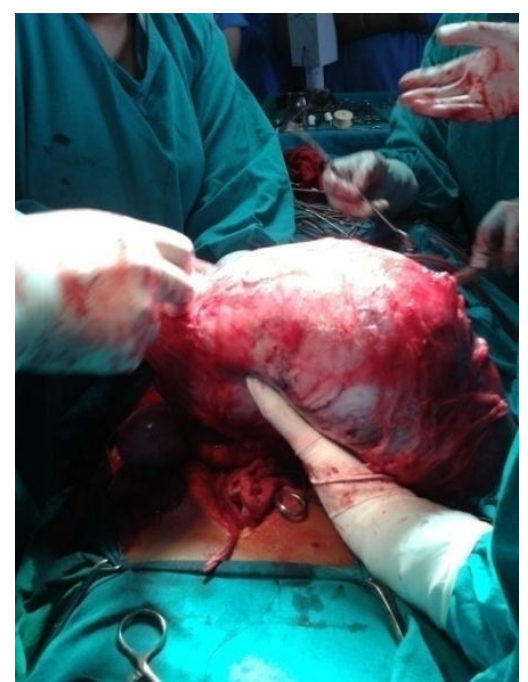

Fig 3: intraoperative picture while enucleation 


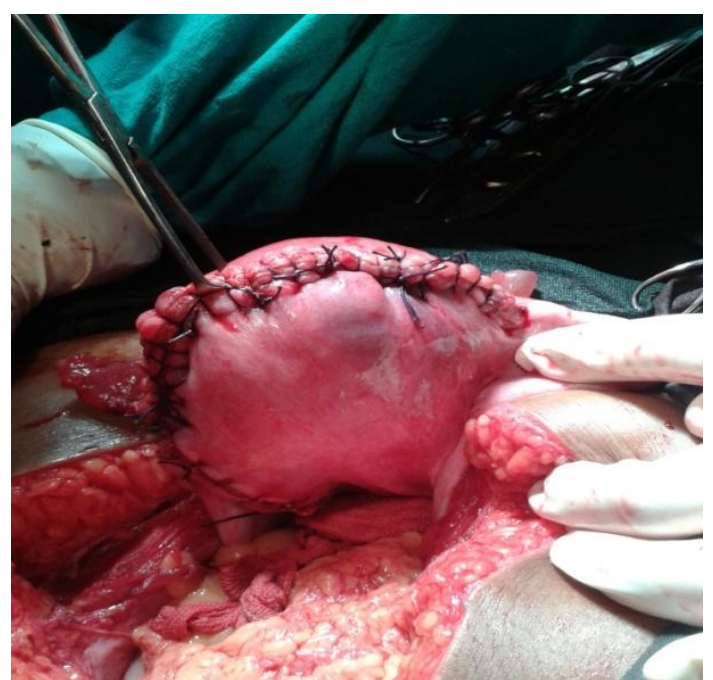

Fig 4: Intra operative picture showing the uterus post myomectomy

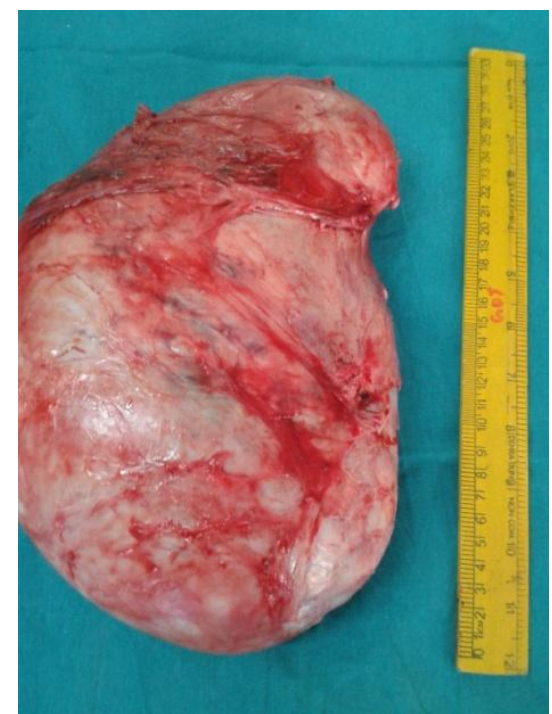

Fig 5: $26 \times 22 \times 10 \mathrm{cms}$ fibroid post enucleation weighing $2.8 \mathrm{kgs}$

\section{Discussion}

Leiomyomata, the most common benign tumors of the female pelvis are more common in African American females, four times more common than Caucasians ${ }^{3,4.4}$ They can be sub mucosal, intramural or sub serous in location. Excessive menstrual bleeding (menorrhagia) leading to anemia, debilitating dysmenorrhea, generalized pelvic pain or symptoms of pressure on the adjacent pelvic viscera may occur, but pain other than dysmenorrhea is typically a late symptom. leiomyomata can be associated with infertility.

Ultrasound is usually the initial screening tool for myomata. Distinguishing leiomyomata from other pelvic masses such as ovarian tumors is done most easily with an endovaginal or abdominal ultrasonographic examination, because they appear solid by sonography, with acoustic impedance similar to that of the normal myometrium. Since the advent of MRI, the precision for identification, number, and location of these tumors as well as differentiation from an adnexal mass is greatly enhanced and in questionable cases it has been judged to be superior to USG. This is especially important when considering myomectomy in patients for whom fertility is an issue. CT is limited to cases of fibroids with complications such as necrosis and malignant transformation. Appropriate counseling and possible myomectomy are recommended in symptomatic patients as well as those with large asymptomatic tumors in an effort to preserve fertility in this younger age group. Most of the reported cases had normal obstetric history following myomectomy. Recently, selective uterine artery embolization has been used successfully to treat uterine myomas. One percent of patients required hysterectomy due to post embolization infection 5. A number of complications have been identified in women during pregnancy subsequent to UAE, such as increased risks for preterm delivery, malpresentation and abnormal placentation ${ }^{6}$. 


\section{Conclusion}

Leiomyomata, most common benign tumors can grow to a very large size causing pressure symptoms without menstrual disturbances. In the above case myomectomy was done and uterus preserved. Myomectomy gives an option to preserve fertility and is an alternative option to hysterectomy

Staff members, Dept of OBG, Dr. PSIMS \& RF

\section{Acknowledgements}

Dept of Pathology

Dept of Radiology

\section{References}

[1] LESLEY L.BREECH AND JOHN A. ROCK: LEIOMYOMATA UTERI AND MYOMECTOMY in wolters kluwer/Lippincott Williams and wilkins TE LINDE'S OPERATIVE GYNAECOLOGY $10^{\text {th }}$ ed: 6688

[2] LESLEY L.BREECH AND JOHN A. ROCK: LEIOMYOMATA UTERI AND MYOMECTOMY in wolters kluwer/Lippincott Williams and wilkins TE LINDE'S OPERATIVE GYNAECOLOGY $10^{\text {th }}$ ed: p688

[3] Van Voorhis BJ, Romitti PA, Jones MP. Family history as a risk factor for development of uterine leiomyomas: result of a pilot study. J Reprod Fibroid uterus. Med. 2002;47:663-669.

[4] Faerstein E, Szklo M, Rosenshein N. Risk factors of uterine leiomyoma:A practice-based case-control study. African-American heritage, reproductive history, body size, and smoking. Am J Epidemiol.2001;153:1-10.

[5] Hughes JL, Reidy JF. Imaging and treatment of uterine fibroids including the role of uterine artery embolisation. Imaging. 2003;15:79-88.

[6] MC GRAW HILL WILLIAMS GYNAECOLOGY 2008 CH 9: pelvic mass p206 